\title{
Abordagem da Violência contra a Mulher no Ensino Médico: um Relato de Experiência
}

\section{Addressing Violence against Women in Medical Education: an Experience Report}

\author{
Dinair Ferreira Machado \\ Kátia Cristina Portero McLellan ${ }^{I I}$ \\ Cristiane Murta-Nascimento ${ }^{I}$ \\ Elen Rose Lodeiro Castanheira ${ }^{I}$ \\ Margareth Aparecida Santini de Almeidal
}

\section{PALAVRAS-CHAVE \\ - Violência contra a Mulher; \\ - Educação Médica; \\ - Aprendizado Baseado em Problemas.}

\section{KEYWORDS}

- Violence against Women;

- Medical Curriculum;

- Problem-Based Learning.
Recebido em: 30/03/2015

Aprovado em:06/06/2016

REVISTA BRASILEIRA DE EDUCAÇÃO MÉDICA

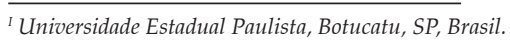

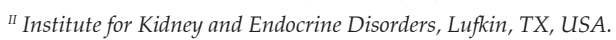




\section{INTRODUÇÃO}

Na atualidade, a violência é reconhecida como um problema de saúde pública de múltiplas causas, multidimensional e com diferentes manifestações. De acordo com documentos da Organização Pan-Americana da Saúde (Opas), a violência adquiriu um caráter endêmico em vários países, dado o número de vítimas com sequelas orgânicas e emocionais ${ }^{1}$.

É no setor saúde, especialmente nos serviços de urgência, que se concentra grande parte das vítimas de violência, já que a maioria desses casos somente chega a esses serviços ou é detectada por eles quando ocorrem traumas e lesões ${ }^{2}$. Além do visível impacto da violência na saúde da população, é importante ressaltar que esse fenômeno ocorre diferentemente entre os grupos populacionais conforme as faixas etárias e, sobretudo, nas relações de gênero. Portanto, pode-se dizer que, durante as fases da vida, o local, o tipo de violência sofrida e o agressor se distinguem entre homens e mulheres.

Em geral, a violência sofrida pelos homens ocorre em ambiente público e tem como principal agressor os próprios homens, enquanto as mulheres, na maior parte das vezes, sofrem violência no âmbito privado, geralmente em seus domicílios, sendo também os homens os principais agressores ${ }^{3}$. De acordo com o mapa da violência em 2012, 91,6\% das vítimas de homicídios eram do sexo masculino, sendo que essa proporção aumenta quando são considerados somente os jovens $(93,3 \%)^{4-6}$.

Embora o número de homicídios das mulheres seja menor em relação ao dos homens, as violências sofridas por elas, muitas vezes, não são computadas nas estatísticas oficiais justamente por não serem reconhecidas suas origens e por se darem de forma velada ${ }^{7,8}$. Ainda assim, estima-se que, nas mulheres entre 15 e 44 anos, a violência causa mais mortes que o câncer, a malária, as guerras e os acidentes de trânsito?

As formas de praticar a violência contra as mulheres incluem desde assassinatos, abusos físicos e sexuais, estupros, a mutilação genital e violência racial e psicológica. Chama atenção também o fato de os agressores, em sua maioria, serem os próprios parceiros na faixa de 30 a 39 anos de idade e serem parceiros atuais ou ex-parceiros das mulheres 9 .

Este fenômeno passou a ter visibilidade a partir do movimento feminista, que, desde a década de 1980, vem impulsionando o interesse das diversas áreas do conhecimento sobre o assunto. A criação das Delegacias de Defesa da Mulher em 1985 e, posteriormente, a promulgação da Lei Maria da Penha em 2006 foram frutos desse movimento e das intensas lutas pela criminalização da violência contra a mulher ${ }^{10}$.

Entre os conceitos utilizados para trabalhar a violência contra a mulher, a violência de gênero vem sendo o mais pertinente para defini-la, pois possibilita uma compreensão am- pliada das relações socialmente construídas entre homens e mulheres com base nas diferenças biológicas e sociais em situações de interação e reciprocidade, e não separadas ${ }^{11,12}$.

Desta forma, o gênero passa a ser pensado sob a perspectiva socialmente modelada, ou seja, a partir das classificações de que características são masculinas e femininas para a socialização dos indivíduos desde os primeiros dias de vida. Além disso, o conceito de violência de gênero também abrange a violência intrafamiliar, praticada por parentes consanguíneos, e a violência doméstica, definida pelo local onde ocorre a agressão ${ }^{11,12}$.

Dada a magnitude do problema, com consequências físicas, psicológicas e sociais, a violência de gênero se configura como um grave problema de saúde pública ${ }^{13}$. Estudos demonstram que as consequências da violência nas condições de saúde das mulheres estão associadas a maiores índices de suicídio, abuso de drogas e álcool, queixas vagas, cefaleia, distúrbios gastrointestinais e sofrimento psíquico em geral, incluindo tentativas de suicídio. Na assistência à saúde, essas mulheres muitas vezes são rotuladas pelos profissionais de saúde como poliqueixosas e histéricas, justamente pela busca frequente por cuidados em saúde ${ }^{14,15}$. No Brasil, a Lei 10.778, de novembro de 2003, instituiu a ficha de notificação compulsória para os casos de violência contra a mulher nos serviços públicos e privados de saúde, passando a ser de responsabilidade dos profissionais de saúde a notificação dos casos ${ }^{16}$.

Contudo, apesar de o problema ganhar legitimidade e reconhecimento mundial nesse setor, as práticas profissionais continuam aquém do recomendado pelas políticas e normatizações de atendimento, especialmente pelos médicos, que, muitas vezes, pautam os atendimentos em um modelo biomédico e pontual, indo na contramão do modelo da clínica ampliada, que abarca as questões biológicas, psicológicas e socioculturais $\mathrm{s}^{15,17,18}$.

Esse cenário contribui para que muitos casos de violência contra a mulher ainda passem despercebidos pelos serviços de saúde, devido à dificuldade dos profissionais em detectá-los, dado o caráter sociocultural do fenômeno.

No cotidiano dos serviços, os sintomas podem ser tratados de forma pragmática e imediatista ou desvendados à luz da história de vida e das relações sociais e familiares. Para isso, o profissional necessita apresentar escuta e visão ampliadas para acolher a queixa de forma integral e interdisciplinar, atuando conjuntamente com profissionais do serviço social e de psicologia e, até mesmo, utilizando recursos externos, como o Judiciário e os meios policiais.

Desta forma, é necessário superar dois desafios para a abordagem dessa problemática na prática médica. O primei- 
ro se refere às práticas profissionais, atualmente pautadas no modelo de atendimento biomédico e pontual; e o segundo consiste em identificar situações de risco que antecedem as urgências e emergências hospitalares. Superar esses desafios e abordar o tema da violência na formação médica vão ao encontro das novas diretrizes curriculares do curso médico ${ }^{19}$.

Contudo, a abordagem do conteúdo violência só resultará em um olhar ampliado por parte do futuro profissional se o processo de ensino-aprendizagem for pautado em método da aprendizagem baseada em problemas, valorizando as experiências e saberes dos estudantes, e construir espaços de diálogos teóricos e práticos, como se buscou com a presente proposta.

Entende-se que o caráter sociocultural da violência contra a mulher perpassa as trajetórias e experiências de vida dos próprios alunos e, portanto, pressupõe compreender o tema em diferentes perspectivas sócio-históricas, justificando, assim, a proposta do método dialógico para um processo de ensino-aprendizagem emancipatório ${ }^{20,21}$.

As discussões teóricas desenvolvidas pautaram-se em referenciais das ciências humanas, sociais, biológicas e jurídicas; e a experiência prática se deu por meio de entrevistas com profissionais que atuam no Sistema Único de Saúde (SUS), na atenção primária, e no Sistema Único de Assistência Social (SUAS), na proteção social especial de média complexidade.

Considerou-se necessário também que os estudantes reconhecessem nos serviços socioassistenciais da Política de Assistência Social, organizados pelo SUAS, potenciais parceiros para o enfrentamento da violência contra as mulheres, justamente porque essa problemática é um dos focos de atenção desta política nos últimos tempos ${ }^{22}$.

Dada a trajetória da política de assistência social no Brasil, a mesma ainda hoje é compreendida pela sociedade e por alguns profissionais como prática assistencialista e pontual junto às camadas mais empobrecidas, desconsiderando assim o potencial de transformação da realidade social e outras questões sociais que vão além das condições socioeconômicas e materiais propostas pela política pós-Constituição de 1988, consolidada com a Política de Assistência Social de $2004^{23}$.

Contudo, a Política Nacional de Assistência Social de 2004, base para concepção e implantação do Sistema Único de Assistência Social em 2011 (SUAS/2011), elucida e explicita o caráter da referida política ao dividi-la em dois eixos: (1) benefícios por meio dos programas de transferência de renda, a exemplo do Bolsa-Família e do benefício de prestação continuada; (2) serviços, ações de caráter contínuo e com o objetivo de empoderamento e emancipação dos indivíduos, famílias e comunidade ${ }^{23,24}$.
Portanto, a partir desses eixos, a política pressupõe duas formas de intervenção. A primeira alia serviços e benefícios, ou seja, busca empoderar e emancipar indivíduos e famílias de baixa renda. A segunda atua com indivíduos e famílias que estão em situação de vulnerabilidade, mas não necessariamente a socioeconômica. A violência contra a mulher se configura como importante exemplo de prática que pode incorporar apenas o eixo serviços, visto que o fenômeno violência ocorre em todos os níveis socioeconômicos ${ }^{23,24}$.

Ressalta-se, ainda, a importância da intersetorialidade nas ações junto à demanda prevista não somente pelas políticas de saúde e de assistência social, mas também pela Lei 11.340/2006 (Lei Maria da Penha), que prevê em seu Art. 9ำ que "as ações prestadas às mulheres em situação de violência devem estar articuladas de acordo com os princípios e diretrizes previstos no Sistema Único de Assistência Social, no Sistema Único de Saúde e no Sistema de Segurança Pública" ${ }^{10}$.

O SUAS e o SUS possuem organização e estrutura semelhantes, ambos são divididos por níveis de atenção e têm como foco de atendimento o território e suas famílias. O SUAS redefiniu os serviços socioassistenciais de modo hierarquizado em dois níveis de atenção: proteção social básica e proteção social especial.

A proteção social básica é representada, nos territórios, pelo Centro de Referência da Assistência Social (CRAS), equivalente à Atenção Primária à Saúde (Unidades de Saúde da Família e Unidades Básicas de Saúde). Estes locais constituem a porta de entrada para a política de assistência social dos municípios e têm a finalidade de fortalecer a função protetiva das famílias, prevenir a ruptura de seus vínculos e realizar a prevenção e promoção dos vínculos familiares e comunitários $^{24}$.

O serviço de proteção social especial se divide em média e alta complexidade. A média complexidade é representada pelo CREAS, cujo nível de atenção equivale ao nível secundário de saúde. A finalidade do CREAS é ofertar serviço especializado continuado às famílias e indivíduos que estejam em situação de risco social e pessoal por causa da violação de direitos e vínculos sociofamiliares fragilizados. As ações do CREAS visam fortalecer os vínculos familiares e comunitários ${ }^{24}$.

Diante desse cenário, a violência contra a mulher foi um dos temas incorporados para debate com estudantes do terceiro ano médico no ano de 2014, em um dos módulos da Disciplina de Saúde Coletiva III. O módulo teve como objetivo possibilitar aos alunos a compreensão dos fundamentos do planejamento e da organização do Sistema Único de Saúde quanto aos cuidados e problemas de saúde pública, resguardando os fundamentos éticos da prática médica. 


\section{MÉTODOS}

Trata-se de um de relato de experiência de docentes da Faculdade de Medicina de Botucatu - Universidade Estadual Paulista (UNESP), acerca do tema violência contra a mulher, trabalhado com 12 alunos do terceiro ano médico. $\mathrm{O}$ tema foi incorporado no Módulo 1 da Disciplina de Saúde Coletiva III por meio de um problema da vida real. O método de ensino foi a aprendizagem baseada em problemas, que considera o protagonismo dos estudantes na busca e construção do conhecimento.

A escolha da educação problematizadora nessa disciplina vem ocorrendo desde 1999, justificada pela importância de aproveitar as experiências significativas dos alunos para a construção do conhecimento em grupo ${ }^{25}$. Desta forma, priorizou-se nesta experiência a aprendizagem por descoberta no intuito de problematizar o tema a partir do conhecimento prévio dos alunos, contribuindo para que eles assimilassem novos conceitos, como violência de gênero, formas de detecção, rede de atendimento das situações de violência, questões jurídicas e leis de proteção ${ }^{21}$.

As atividades direcionaram-se de acordo com os princípios gerais da aprendizagem baseada em problemas: (1) ensino centrado no aluno e visando fortemente ao seu processo de aprender; (2) responsabilização do aluno por sua aprendizagem; (3) consideração de aprendizagens anteriores; (4) aprendizagem ativa, interativa e colaborativa ${ }^{26,27}$.

Foram incluídas aulas dialogadas para fundamentação teórica, leitura de material didático, discussões em grupo, entrevistas e observação de situações concretas.

A Disciplina de Saúde Coletiva III ocorre ao longo de todo o terceiro ano médico e se divide em quatro módulos: (1) Planejamento de intervenções em problemas de Saúde Pública; (2) Nutrição em Saúde Pública; (3) Encontros com a Ética; (4) Organização da Atenção à Saúde. Atualmente, os estudantes estão divididos em sete turmas de 12 estudantes.

No Módulo 1 - Planejamento de intervenções em problemas de Saúde Pública, no qual se discutiu o tema do presente relato de experiência, as atividades apresentam as seguintes características: Aulas teóricas: Os conteúdos são utilizados para fundamentar as reflexões e desenvolver a capacidade crítica, para, posteriormente, confrontá-la com a prática. Atividades em grupo com o professor-tutor: São as atividades centrais. Compõem-se de apresentação de conteúdos teóricos, discussão que correlaciona o tema discutido com outros conhecimentos e práticas, entrevistas e visitas a instituições de saúde. Apresentação em grupo misto: Ao final do módulo, cada aluno apresenta a síntese do trabalho desenvolvido no seu grupo em novos grupos compostos por alunos de todos os grupos. Essa atividade visa: propiciar aos alunos a oportunidade de conhecerem o trabalho dos outros grupos, por meio do relato das diferentes experiências; estimular o aluno a se apropriar do conteúdo elaborado no seu grupo e a desenvolver a capacidade de apresentar os pontos fundamentais de forma sintética; desenvolver a habilidade de comunicação oral.

Os estudantes são avaliados de maneira formativa, conforme a participação em cada atividade; avaliação da apresentação oral individual no grupo misto; avaliação do relatório individual do trabalho do grupo; e avaliação escrita individual sobre o tema.

Em 2014, as atividades do Módulo 1 foram desenvolvidas de janeiro a abril por meio de dez encontros semanais nos quais se realizaram as seguintes atividades: (a) leitura crítica do caso de uma mulher em situação de violência, identificação das possíveis causas e reflexões sobre a literatura do tema; (b) visitas a dois serviços de Atenção Primária à Saúde (Unidade Básica de Saúde tradicional e Unidade de Saúde da Família) e ao Centro de Referência Especializado de Assistência Social (CREAS); (c) sistematização dos dados teóricos e práticos, e construção da árvore explicativa do problema e do planejamento estratégico; (d) apresentação do caso de violência contra a mulher e a trajetória de atividades realizadas pelo grupo para os demais estudantes.

\section{RELATANDO A EXPERIÊNCIA}

Leitura crítica de um caso de violência contra a mulher e imersão teórica

No primeiro encontro, os alunos leram o caso de uma mulher em situação de violência implícita: "Mulher de 36 anos, professora, mãe de dois filhos, de 5 e 11 anos. Frequentadora assídua da Unidade de Saúde da Família, nos atendimentos refere dores de cabeça, dores na pelve, ansiedade, tristeza, dificuldades de cuidar da casa e dos filhos. Além disso, se queixa de insônia, pesadelos, desânimo e falta de apetite. Já foi convocada várias vezes pela escola por causa da indisciplina e do comportamento agressivo dos filhos, os quais inclusive foram encaminhados ao posto para atendimento psicológico. Exames laboratoriais normais, mas sem melhora no tratamento".

Posteriormente, foi utilizada a técnica de brainstorming ("tempestade de ideias") para explorar as possibilidades de ideias criativas do grupo sobre o tema da violência contra a mulher.

Geralmente, essa técnica é utilizada nas Ciências Sociais e humanas com o objetivo de suscitar novas ideias sobre determinado tema e estratégias de solução. O uso em grupo se torna mais eficaz porque desperta um número maior de ideias 
do que individualmente, contribuindo, assim, para ampliar o conhecimento do grupo ${ }^{28-31}$.

Em seguida, diante da diversidade de sugestões e hipóteses levantadas, o grupo descartou algumas ideias e aglutinou outras por similaridade. Desta forma, os estudantes elencaram e classificaram os determinantes biopsicossociais que envolvem as mulheres em situação de violência e o papel dos serviços de saúde, dividindo-os, para aprofundamento teórico, nos seguintes temas: (a) construção histórica e social da violência contra a mulher; (b) criminalização da violência contra a mulher; (c) violência e seu impacto na saúde das mulheres; (c) serviços de atenção primária e a violência contra a mulher.

Com base nesses temas, cada dupla de estudantes trouxe, no encontro seguinte, questões teóricas que foram problematizadas no grupo. O movimento feminista foi destacado como um divisor de águas para o reconhecimento da violência contra a mulher e para a criação da Lei de coibição dessa forma de violência. Entre os determinantes que impactam o processo de saúde e de doença das mulheres em situação de violência, foram destacados: depressão, ansiedade, crises de pânico, insegurança e baixa autoestima.

Os estudantes também conseguiram perceber fatores que podem predispor as mulheres a sofrer violência, como: uso de álcool e outras drogas pelo agressor, desemprego, socialização dos gêneros, dependência financeira e medo. Quanto aos serviços de atenção primária, a discussão focalizou a invisibilidade do problema para os serviços de saúde; a falta de capacitação dos profissionais para detectarem um problema de cunho social; o modelo de atendimento baseado no biológico; e a ausência de discussão do tema na graduação médica. Além disso, foi discutida a importância de um trabalho intersetorial como estratégia de ação para intervenção sobre o tema.

\section{As visitas}

\section{Impressões da visita ao Centro de Referência Especializado em Assistência Social (CREAS)}

O CREAS foi um dos serviços visitados pelos alunos. Antes da visita, foram problematizadas, em aula, a organização da política de assistência social e a consolidação do Sistema Único de Assistência Social, por meio dos serviços de proteção social básica e proteção social especial.

No município de Botucatu, o CREAS formalizou parceria com a Delegacia de Defesa da Mulher (DDM) com o objetivo de realizar a busca ativa dos casos de mulheres em situação de violência. Mensalmente, são encaminhadas cópias dos Boletins de Ocorrência dessa natureza aos profissionais de referência no CREAS, para que se realize a busca ativa e o atendimento oportuno a essas mulheres.
A visita a esse local possibilitou aos alunos compreender o funcionamento do SUAS e conhecer as ações desenvolvidas pelo CREAS do município. Além disso, os alunos reconheceram as interfaces com a saúde, apreendendo, mais especificamente, a dinâmica e as implicações que envolvem as ações de saúde e de assistência social nos casos de violência contra a mulher. Essa vivência despertou nos alunos um olhar intersetorial e uma perspectiva para além dos serviços de saúde, mas que pode impactar a saúde diretamente.

\section{Impressões da visita à Unidade Básica de Saúde (UBS)}

O outro serviço visitado foi uma policlínica constituída por equipe multiprofissional, área de abrangência extensa e livre demanda. Nessa visita, os estudantes perceberam a dificuldade da equipe em detectar a violência contra a mulher. De acordo com o relato da equipe de enfermagem, não havia casos de violência contra a mulher naquela região. A UBS em questão está localizada numa região do município com alta prevalência de prostituição, e, portanto, esperava-se encontrar uma proporção considerável de casos de mulheres em situação de violência. Uma das hipóteses para a ausência de registro de casos de agressão poderia estar relacionada à agressão velada, ou seja, a não procura das profissionais do sexo por atendimento médico e a não apresentação de notícia-crime à polícia. De acordo com a reflexão realizada pelo grupo, os profissionais da unidade de saúde não estariam preparados para identificar as questões de violência por trás das comorbidades físicas devido à falta de escuta e de acolhimento da demanda de maneira holística.

\section{Impressões da visita à Unidade de Saúde da Família (USF)}

O último serviço visitado foi uma Unidade de Saúde da Família, que, diferentemente da policlínica, não referiu dificuldades na detecção dos casos de violência contra a mulher. Segundo os estudantes, neste serviço, a equipe estava apta a detectar os casos por detrás das queixas e procuras recorrentes na demanda espontânea. Outros fatores apontados que poderiam favorecer a detecção dos casos de violência na USF foram a presença do agente comunitário de saúde, o vínculo e a proximidade da população atendida.

Em relação ao vínculo, a figura do agente comunitário foi considerada de grande importância. Por se tratar de um indivíduo da comunidade, que faz visitas periódicas às famílias, as vítimas podem ter esse profissional como uma figura de confiança, com quem se sentem confortáveis em expor suas demandas.

Durante a entrevista, foi enfatizada, ainda, a importância do trabalho conjunto com os Núcleos de Apoio à Saúde da Fa- 
Figura 1

Árvore de causas proposta pelo grupo de estudantes do terceiro ano médico sobre a violência contra a mulher

Árvore das Causas

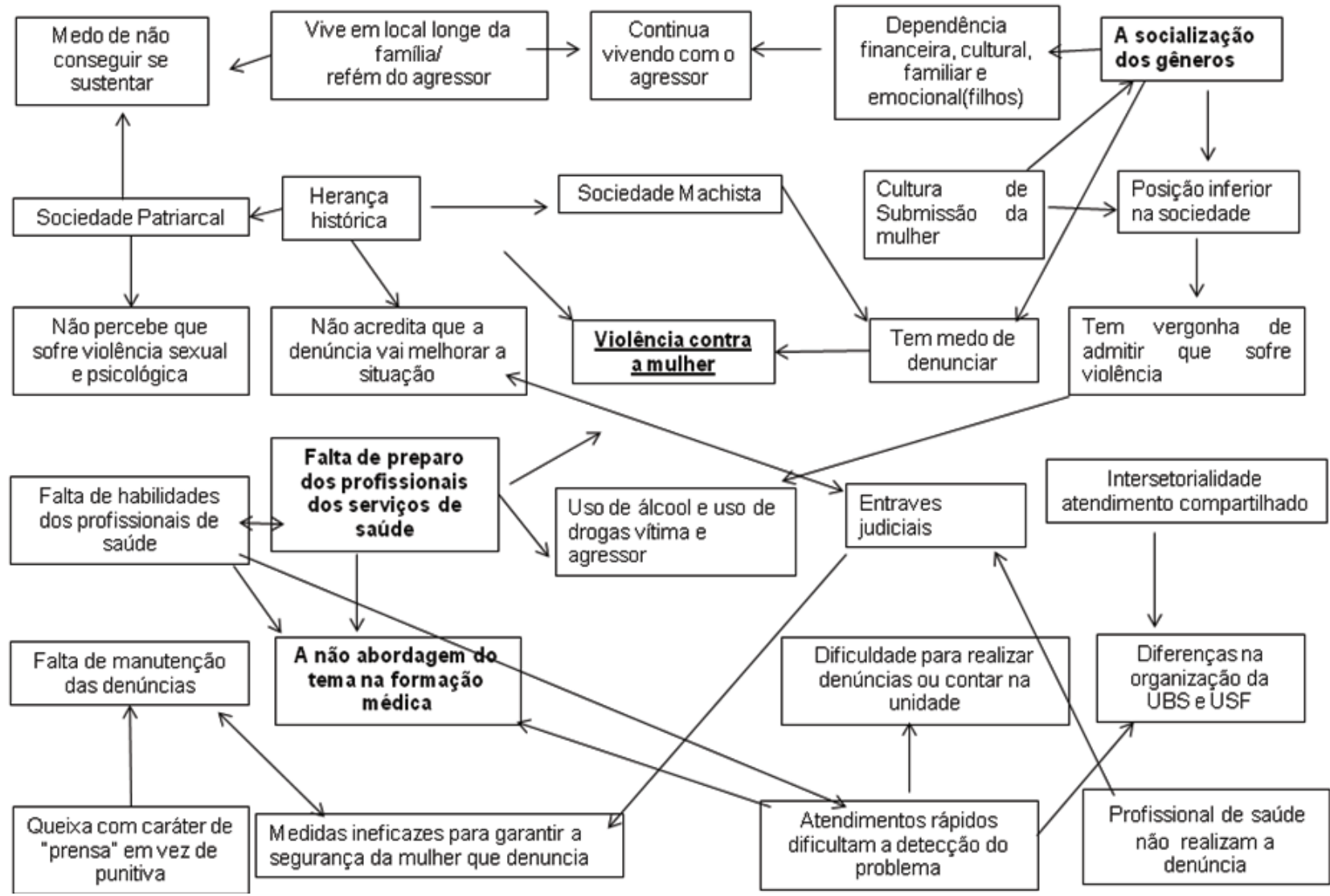

mília (Nasf), que também podem contribuir para o atendimento desses casos, tendo em vista o caráter multiprofissional da equipe.

Sistematização dos dados teóricos e práticos, construção da árvore de causas e da planilha de operações

Após a leitura do caso, busca e reflexão de estudos científicos sobre o tema na literatura e visitas aos serviços do município que atendem à referida demanda, o grupo de estudantes, mediado pelo docente, construiu uma árvore de causas sobre o fenômeno.

As diferentes explicações destacadas pelo grupo na árvore de causas (Figura 1) foram agrupadas nas seguintes dimensões: (a) questões socioculturais: cultura de submissão, dependência financeira e afetiva do companheiro, herança intergeracional, forma de socialização patriarcal e não entende as agressões como forma de violência; (b) dificuldade de detecção e acompanhamento da violência pelos profissionais dos serviços de saúde: a mulher sente vergonha de relatar a situação; medo de ser julgada pelos profissionais; falta de preparo dos profissionais, os profissionais não sabem como proceder diante dos casos, atendimentos rápidos e pontuais dificultam a detecção; os profissionais não utilizam e/ou não sabem da rede de apoio intersetorial; falta de abordagem do tema na graduação médica; (c) política e legislação: as mulheres não realizam a denúncia ou não a mantêm; medo de denunciar as agressões; medidas judiciais ineficazes; medo, por parte dos profissionais, de denunciar a situação.

Após análise da árvore de causas e suas relações, o grupo estabeleceu uma planilha de operações com propostas concretas de ações que compreenderam o alicerce da problemática em termos socioculturais e interventivos (Quadro 1). 


\begin{tabular}{|c|c|c|c|}
\hline \multicolumn{4}{|c|}{$\begin{array}{l}\text { QUADRo } 1 \\
\text { postas de ações construídas pelo grupo }\end{array}$} \\
\hline Nó crítico & Ação & Facilidades & Responsáveis \\
\hline Socialização dos gêneros & $\begin{array}{l}\text { Oficinas periódicas sobre a } \\
\text { construção social dos gêneros } \\
\text { (papéis masculino e feminino) }\end{array}$ & $\begin{array}{l}\text { - Abrangência do tema nos } \\
\text { territórios } \\
\text { - População, profissional e local } \\
\text { para trabalhar com o tema na } \\
\text { comunidade (USF/UBS/CRAS/ } \\
\text { CREAS) }\end{array}$ & $\begin{array}{l}\text { Profissionais de saúde, da } \\
\text { assistência social e alunos da } \\
\text { Faculdade de Medicina de } \\
\text { Botucatu }\end{array}$ \\
\hline $\begin{array}{l}\text { Falta de preparo dos } \\
\text { profissionais dos serviços de } \\
\text { saúde }\end{array}$ & $\begin{array}{l}\text { - Educação permanente por } \\
\text { meio de cursos e oficinas } \\
\text { - Matriciamento dos casos pela } \\
\text { equipe do CREAS }\end{array}$ & $\begin{array}{l}\text { - Público-alvo disponível e } \\
\text { definido } \\
\text { - Profissionais de referência } \\
\text { do CREAS capacitados para } \\
\text { matriciamento e apoio }\end{array}$ & $\begin{array}{l}\text { Prefeitura (Secretarias da Saúde } \\
\text { e da Assistência Social) } \\
\text { Apoio dos especialistas da } \\
\text { FMB/Botucatu }\end{array}$ \\
\hline $\begin{array}{l}\text { Não abordagem do tema na } \\
\text { formação médica }\end{array}$ & $\begin{array}{l}\text { Inserção do tema nas aulas de } \\
\text { Saúde Coletiva para o terceiro } \\
\text { ano médico }\end{array}$ & $\begin{array}{l}\text { - Mudança nas grades } \\
\text { curriculares da Medicina } \\
\text { - Disponibilidade de } \\
\text { conhecedores do assunto }\end{array}$ & $\begin{array}{l}\text { Departamento de Saúde Pública } \\
\text { da Faculdade de Medicina de } \\
\text { Botucatu }\end{array}$ \\
\hline
\end{tabular}

Neste sentido, foram selecionados três nós críticos para o exercício de intervenção: socialização dos gêneros; falta de preparo dos profissionais da rede de serviços de saúde; não abordagem do tema na formação médica.

O primeiro nó crítico - "socialização dos gêneros" - foi selecionado tendo em vista que os estudantes acreditaram que essa seria uma estratégia abrangente e inovadora de transformação para as mulheres e para os profissionais envolvidos. De acordo com a percepção do grupo, o tema permite uma visão sócio-histórica das relações estabelecidas entre os gêneros ao longo do tempo, fator que pode contribuir para a desmistificação dos rótulos e preconceitos que pairam sobre as mulheres em situação de violência. Além disso, possibilita que os profissionais realizem ações de promoção e prevenção da violência contra a mulher, com maior aproximação e vínculo.

$\mathrm{O}$ intuito dessa operação visa envolver os profissionais das Unidades de Saúde da Família e as mulheres por eles atendidas em atividades que os façam refletir sobre as mudanças e transformações históricas da mulher no mundo do trabalho e nas relações familiares. O foco da transformação está no empoderamento da mulher para protagonizar a busca de apoio nas diferentes instituições. A facilidade dessa operação está no público já definido pelo território de adstrição da Unidade de Saúde da Família.

A segunda operação visou mudanças no processo de trabalho dos profissionais que atuam na Atenção Primária à Saúde e tem como base a educação permanente, preconiza cursos e oficinas sobre a forma de abordar e prevenir a violência contra a mulher de maneira continuada. Prevê, ainda, o envolvimento dos profissionais de referência do CREAS para o matriciamento e compartilhamento das situações já instaladas. A principal facilidade dessa operação foi ter o apoio técnico da equipe do CREAS, que é especializada no atendimento de mulheres nessa situação. Contudo, a falta de adesão dos profissionais de saúde, por não compreenderem a importância do tema, poderia ser uma das dificuldades.

A terceira operação envolveu a inserção do tema "violência contra a mulher" na grade curricular do ensino médico. Essa foi uma proposta unânime do grupo após perceber as dificuldades dos profissionais em abordar o tema e detectá-lo em sua complexidade biopsicossocial, e não apenas fisiológica. Essa operação, por sua vez, necessita de um prazo maior para ser implantada, pois envolve mudança curricular e exige envolvimento de diferentes órgãos. Contudo, iniciativas como essa de trazer o tema para problematização numa disciplina já existente, contextualizando com diferentes cenários, ou mesmo a possibilidade de ofertar cursos de extensão com esse tema já contribuem para um conhecimento mais crítico e reflexivo dos graduandos a esse respeito.

Apresentação do caso de violência contra a mulher e a trajetória de atividades realizadas pelo grupo para os demais estudantes

Ao apresentar o caso e problematizar as atividades realizadas no decorrer do módulo para os demais estudantes, foi possível identificar no grupo habilidades e competências desenvolvidas com a experiência.

As leituras, discussões e visitas possibilitaram aos estudantes desenvolver habilidades de análise sociocultural do tema, verificando a pertinência de sua aplicação na saúde pú- 
blica, mais especificamente na atenção primária, direcionando o olhar para além da queixa instalada e se comprometendo com a integralidade do cuidado.

A discussão sobre o conceito de violência também surtiu efeito positivo no grupo de estudantes, uma vez que conseguiram perceber que, mesmo entre eles, havia diferentes formas de entender a violência. Essa situação, por sua vez, estendeu os olhares para além das próprias experiências pessoais e culturais, trazendo para o cenário inquietações sobre a organização e definição dos papéis femininos e masculinos no decorrer dos anos e nas diferentes camadas sociais. Portanto, eles desenvolveram a habilidade de trabalhar em grupo, respeitando as diferentes experiências e aprendizados naquele contexto.

Nesse sentido, os estudantes puderam reconhecer a prática da violência contra a mulher como um problema de saúde pública por sua magnitude e, também, pelo reconhecimento do impacto que causa no processo saúde-doença. Antes disso, reconheceram a intrínseca ligação do fenômeno com o contexto histórico e sociocultural. $\mathrm{O}$ fator considerado de maior relevância pelo grupo foi a necessidade de detectar e trabalhar os casos no primeiro nível de atenção e a articulação com a rede intersetorial.

Uma postura profissional de acolhimento foi destacada pelos estudantes como uma estratégia de aproximação e interação médico-paciente para concretizar o protagonismo das mulheres na superação da violência.

Ao final das atividades, foi possível perceber a incorporação de novos conceitos e olhares sobre o tema. Além disso, no relatório final, bem como nos grupos mistos, os alunos se manifestaram sensibilizados e mais habilitados para identificar, avaliar, acompanhar e encaminhar casos de violência contra a mulher.

\section{CONSIDERAÇÕES FINAIS}

Nesta experiência, observou-se que, embora a violência contra a mulher seja tema claramente reconhecido como um problema de saúde pública, ainda não foi assimilado pelos profissionais da saúde e não tem sido aplicado no cotidiano dos serviços, dadas as dificuldades em incorporar, na prática, demandas que vão além do biológico.

Percebe-se que o grande desafio está no processo de formação desses profissionais, que, provavelmente, tiveram uma aprendizagem baseada em condutas pontuais e fragmentadas.

Portanto, desde a graduação, é necessário trabalhar as dimensões sociofamiliares e socioculturais que se escondem por trás de sintomas fisiológicos de mulheres em situação de violência, tendo em vista que cabe ao profissional o desafio de decifrá-los, já que as mulheres não enxergam os serviços de saúde como local apropriado para expor a demanda.
Apreender essas dimensões significa concretizar as práticas em consonância com os princípios e diretrizes do SUS, sendo que, para a experiência em questão, destacaram-se três em especial: acesso universal e equidade; integralidade e humanização do cuidado; cuidado centrado na pessoa sob cuidado na família e na comunidade.

É importante ressaltar que esses entraves já estão sendo equacionados pelos órgãos responsáveis pela graduação do curso médico, tanto no atual currículo, como na proposta da reforma curricular em fase final de elaboração, caminhando em consonância com as novas Diretrizes Curriculares Nacionais dos Cursos de Medicina, instituídas em junho de 2014. De acordo com esse documento, a formação do graduado deve abranger as áreas de atenção à saúde, gestão em saúde e educação em saúde. O Artigo $5^{\circ}$ preconiza que as ações do futuro médico abranjam as dimensões da diversidade: biológica, subjetiva, étnico-racial, socioeconômica, sociocultural, de gênero e de orientação social, e demais aspectos da diversidade humana que singularizam cada indivíduo ou grupo ${ }^{19}$.

Ao final do Módulo 1 da Disciplina de Saúde Coletiva III, os estudantes apresentaram diferentes percepções do fenômeno e sua relação para o processo saúde-doença. Também conseguiram entender a importância de garantir o acesso universal às mulheres em situação de violência, livre de preconceitos, julgamentos, de acordo com suas necessidades individuais e suas histórias de vida. Além disso, compreenderam que o atendimento integral e humanizado demanda interação constante e contínua entre o profissional e a mulher em um processo de construção do protagonismo e empoderamento feminino no âmbito familiar, social e comunitário.

Finalmente, reconheceram que a consolidação desses preceitos exige dos profissionais uma formação para o olhar ampliado e a percepção da problemática, para a construção e o estabelecimento de vínculos, e, sobretudo, para a definição de estratégias de intervenção que vão além dos serviços de saúde. $\mathrm{O}$ uso desse caso possibilitou aos estudantes a compreensão das interfaces entre a violência contra a mulher, a segurança pública e as questões socioculturais, assim como a rede de apoio instalada para o atendimento dos casos que abrangem outras políticas, especialmente a de assistência social.

\section{REFERÊNCIAS}

1. Organização Panamericana da Saúde. Violência y salud: resolución no XIX. Washington: OPAS; 1994.

2. Organização Mundial da Saúde. Relatório mundial sobre violência e saúde. Brasília: OMS, OPAS; 2002.

3. Machado DF. A experiência com a violência urbana entre adolescentes de Botucatu/SP. Botucatu; 2005. Mestrado 
[Dissertação] - Faculdade de Medicina de Botucatu, Universidade Estadual Paulista.

4. Mello Jorge MHP. Como morrem nossos jovens. In: Comissão Nacional de População e Desenvolvimento. Jovens acontecendo na trilha das políticas públicas. Brasília: CNPD; 1998.

5. Minayo MC. A Violência social sob a perspectiva da saúde pública. Cad Saúde Pública 1994;10(1):7-18.

6. Waiselfisz JJ. Juventude viva os jovens do Brasil. Brasília: Secretaria-Geral da Presidência da República; 2014. (Mapa da violência 2014).

7. Berger SMD. Violência entre parceiros íntimos: desafios no ensino e atenção em saúde. Rev Bras Educ Med 2011;35(4): 526-34.

8. Brasil. Presidência da República. Secretaria de Políticas para as Mulheres. Secretaria Nacional de Enfrentamento à Violência contra as Mulheres. Política Nacional de Enfrentamento à Violência Contra as Mulheres. Brasília; 2011.

9. Gomes R, Minayo MCS, Silva CFR. Violência contra a mulher: uma questão transnacional e transcultural das relações de gênero. In: Impacto da violência na saúde dos brasileiros. Brasília: Ministério da Saúde, Secretária de Vigilância em Saúde; 2005. 340 p. (Série B. Textos Básicos de Saúde).

10. Brasil. Presidência da República. Casa Civil. Lei Maria da Penha. Lei n. 11.340/2006. Coíbe a violência doméstica e familiar contra a mulher. Brasília; 2006.

11. Saffioti HIB. Violência contra a mulher e violência doméstica. In: Bruschini C, Unberhaum SG, organizadoras. Gênero, democracia e sociedade brasileira. São Paulo: Fundação Carlos Chagas, Editora 34; 2002. p. 321-38.

12. Santos CMD, Izumino WP. Violência contra as mulheres e violência de gênero: notas sobre estudos feministas no Brasil. Rev Estud Interdiscipl Am Latin El Caribe 2005;16(1):147-64.

13. Schraiber LB, D'Oliveira AFPL, Franca-Junior I, Pinho AA. Violência contra a mulher: estudo em uma unidade de atenção primária à saúde. Rev Saúde Pública 2002;36(4):470-7.

14. Schraiber LB, D'Oliveira AFPL. Violência contra mulheres: interfaces com a saúde. Interface (Botucatu) 1999;3(5):1-27.

15. Kiss LB, Schraiber LB. Temas médico-sociais e a intervenção em saúde: a violência contra mulheres no discurso dos profissionais. Ciênc Saúde Colet [on line]. 2011. 16(3) [capturado 17 dez. 2013]; 1943-52. Disponível em <http:// www.scielo.br/scielo.php?script=sci_arttext\&pid=S1413$-81232011000300028 \& \operatorname{lng}=p t \& n r m=i s o>$.

16. Brasil. Lei $\mathrm{n} ² 0.778$ de 24 de novembro de 2003. Estabelece a notificação compulsória, no território nacional, do caso de violência contra a mulher que for atendida em serviços de saúde públicos ou privados. Diário Oficial da República Federativa do Brasil. Brasília, 24 nov. 2003.

17. D'Oliveira AFPL, Schraiber LB, Hanada H, Durand J. Atenção integral à saúde de mulheres em situação de violência de gênero - uma alternativa para a atenção primária em saúde. Ciênc Saúde Colet 2009;14(4):1037-50.

18. Signorelli MC, Auad D, Pereira PPG. Violência doméstica contra mulheres e a atuação profissional na atenção primária à saúde: um estudo etnográfico em Matinhos, Paraná, Brasil. Cad Saúde Pública [on line]. 2013. 29(6) [capturado 18 dez. 2013];1230-40. Disponível em: <http://www.scielo.br/scielo.php?script=sci_arttext\&pid=S0102-311X2013 000600019\&lng=pt\&nrm=iso $>$.

19. Brasil. Ministério da Educação e Cultura. Conselho Nacional de Educação. Resolução CNE/CES nํㅜ 3, de 20 de junho de 2014. Institui Diretrizes Curriculares Nacionais do Curso de Graduação em Medicina e dá outras providências [Internet]. Brasília: MEC; 2014 [capturado 21 fev 2016]. Disponível em: http://portal.mec.gov.br/index.php? option=com docman\&view =download \&alias $=15874-$ rces $003-$ -14\&category_slug=junho-2014-pdf\&Itemid=30192

20. Freire P. Pedagogia do oprimido. Rio de Janeiro: Paz e Terra; 1975.

21. Cyrino EG, Toralles-Pereira ML. Trabalhando com estratégias de ensino-aprendizado por descoberta na área da saúde: a problematização e a aprendizagem baseada em problemas. Cad Saúde Pública [on line]. 2004. 20(3) [capturado 03 mar. 2016];780-8. Disponível em: http:/ / www.scielo.br/scielo.php?script=sci_arttext\&pid=S0102-311X200 4000300015\&lng=en\&nrm=iso.

22. Brasil. Ministério do Desenvolvimento Social e Combate à Fome. Tipificação Nacional dos Serviços Socioassistenciais: reimpressão 2013: Resolução n.109 de 11 de novembro de 2009. Brasília: Conselho Nacional de Assistência Social; 2013.

23. Brasil. Ministério do Desenvolvimento Social e Combate à Fome. Política Nacional de Assistência Social. Brasília: MDS; 2004.

24. Brasil. Ministério do Desenvolvimento Social e Combate à Fome. Norma Operacional Básica: NOB/SUAS: construindo as bases para a implantação do Sistema Único de Assistência Social. Brasília, DF: MDS; 2005.

25. Cyrino EG, Rizzato ABP. Contribuição à mudança curricular na graduação da Faculdade de Medicina de Botucatu. Rev Bras Saude Mater Infant [on line]. 2004. 4(1) [capturado 29 fev. 2016];59-69. Disponível em: http:// www.scielo.br/scielo.php?script=sci_arttext\&pid= S1519$-38292004000100006 \& \operatorname{lng}=$ pt\&nrm=iso. 
26. Barrows HS. Problem-based learning in medicine and beyond: a brief overview. In: Wilkerson L, Gilselaers H, editors. Bringing problem-based learning to higher education: theory and practice. San Franscisco, CA: Jossey-Bass Inc.; 1996. p. 3-11.

27. Ribeiro LR. Aprendizagem baseada em problema (PBL): uma experiência no ensino superior. São Carlos: EduFSCar; 2008

28. Boy GA. The group elicitation method for participatory design and usability testing. Interactions [on line]. 1997. 4(2) [capturado 19 abr. 2007]; 27-33. Disponível em: http:/ / portal.acm.org/citation.cfm?doid=245129.245132.

29. Minicucci A. Técnicas do trabalho de grupo. 3. ed. São Paulo: Atlas; 2001.

30. Felder RM, Brent R. Effective strategies for cooperative learning. J Coop Collab Coll Teach 2001;10(2):69-75.

31. Coutinho CP, Bottentuit Junior J. Utilização da técnica do Brainstorming na introdução de um modelo de E/B-Learning numa escola Profissional Portuguesa: a perspectiva de professores e alunos [on line] [capturado 03 mar. 2016]. Disponível em: https://repositorium.sdum.uminho.pt/ bitstream/1822/7351/1/Discurso,metodologia $\% 20 \mathrm{e} \% 20$ tecnologia.pdf.pdf.

\section{CONTRIBUIÇÃO DOS AUTORES}

Dinair Ferreira Machado: concepção do artigo, revisão bibliográfica, redação final do texto. Cristiane Murta-Nascimento, Kátia Cristina Portero McLellan, Elen Rose Lodeiro Castanheira e Margareth Aparecida Santini de Almeida: revisão bibliográfica, elaboração e revisão final do texto.

\section{CONFLITO DE INTERESSES}

Declarou não haver.

\section{ENDEREÇO PARA CORRESPONDÊNCIA}

Dinair Ferreira Machado

Av. Prof. Montenegro, s/n ${ }^{\circ}$

Distrito de Rubião Jr. - Botucatu

CEP 18618-970 - SP

E-mail: dinamachado@fmb.unesp.br; asdinamachado@yahoo. com.br 